\title{
SPECIAL ISSUE INTRODUCTION: RESEARCH IN SUSTAINABLE TRANSPORT INTERCHANGES
}

\author{
Prof. Irina Yatskiv (Jackiva) ${ }^{1}-$ Responsible Editor \\ Prof. Eftihia Nathanail ${ }^{2}$ - Guest Editor \\ Prof. Klaus Richter ${ }^{3}$ - Guest Editor \\ ${ }^{I}$ Transport and Telecommunication Institute (TTI) \\ Lomonosova iela 1, Riga, Latvia \\ Jackiva.I@tsi.lv \\ ${ }^{2}$ University of Thessaly, Department of Civil Engineering \\ Pedion Areos, GR-38334 Volos, Greece \\ enath@uth.gr \\ ${ }^{3}$ Fraunhofer Institute for Factory Operation and Automation IFF Magdeburg, Germany \\ klaus.richter@iff.fraunhofer.de
}

\begin{abstract}
This introductory paper gives the readers a brief description of the scope and contents of this Special Issue that consists of papers devoted to Sustainable Transport Interchanges and intermodal networks. The issue depicts the results of the EU project ALLIANCE, which addresses the topic of intermodal interconnections and presents the results of the international collaboration teams, which were established within the context of the project.
\end{abstract}

Keywords: intermodality, interchange, urban mobility, smart solutions, decision-making

In the recent years, European research addressed the topics of intermodality with emphasis on transport interchanges, both for passengers and freight. It was concluded that organizational and institutional structures, decision-making schemes, infrastructural and technological solutions are the main dimensions concerning intermodality. Intermodal integration is considered among the main quality characteristics of the future transport systems and foresees initiatives for the elimination of important obstacles and bottlenecks that obstruct the improvement and cohesion in key aspects of transport, i.e. infrastructure, investments, harmonization of legal frameworks, etc.

This Special Issue is a synthesis of the papers presented by research collaboration teams, which were established in the frame of ALLIANCE project, supported by the EU HORIZON 2020 TWINNING Programme (http://alliance-project.eu/). The main objectives of the project are to:

- help develop advanced research and higher education institution in the field of transport in Latvia, by linking the Transport and Telecommunication Institute (TTI), Latvia with two internationally recognized research entities - University of Thessaly (UTH), Greece and Fraunhofer Institute for Factory Operation and Automation (IFF), Germany and

- facilitate transfer of knowledge in smart solutions for sustainable intermodal transportation networks, and transport interchanges.

Intermodality's relative objectives, as playing a very important role in the "Roadmap to a Single European Transport Area - Towards a competitive and resource efficient transport system" (European Commission, 2011), include the integration of a European high-speed rail network, the shift of road freight transport over $300 \mathrm{~km}$ to other modes (i.e. rail or waterborne) and the connection of all core airports to the rail network. In terms of the legal framework, transport legislation and the integration of a harmonized regulatory framework among EU countries are considered of high importance for the effective linkage amongst various modes and the promotion of intermodal passenger and freight transport.

ALLIANCE addresses the topic of intermodal interconnections, thus interchanges for passenger mobility and freight transportation, taking into account legal and organizational issues, interaction with other domains, such as with the one of spatial planning and economic development, identifies smart and sustainable solutions for achieving smooth and seamless transportation, and exploits decision-making 
strategies, methodologies and techniques for assessing and evaluating the impact of these solutions on the transportation domain, as well as the economy and society (ALLIANCE Deliverable D5.5, 2017).

ALLIANCE conveys knowledge about smart solutions for the interconnection of intermodal networks, through the development of educational and training activities addressed to current and future researchers and stakeholders of passenger and freight interchanges, and the establishment of procedures for ensuring preparation and continuous evolution of publishable research work.

The purpose of the knowledge sharing strategy (Yatskiv et al., 2017) is the clear definition of the activities and tools which have been implemented in order to support effective knowledge sharing and transfer from UTH and IFF to TTI. This strategy set a collaborative research roadmap development with reference to impact factors of the project. The scientific excellence task results of knowledge transfer activities are the main measurable outputs of the project, directly connected with published work and impact factors. The special issue covers mainly a broad range of topics in the field of sustainable transport interchanges and includes research results from collaborative research teams, which were established during ALLIANCE Project lifecycle (training schools, summer schools etc.).

A grid of the project's and this issue's main topics is depicted in the Figure 1.

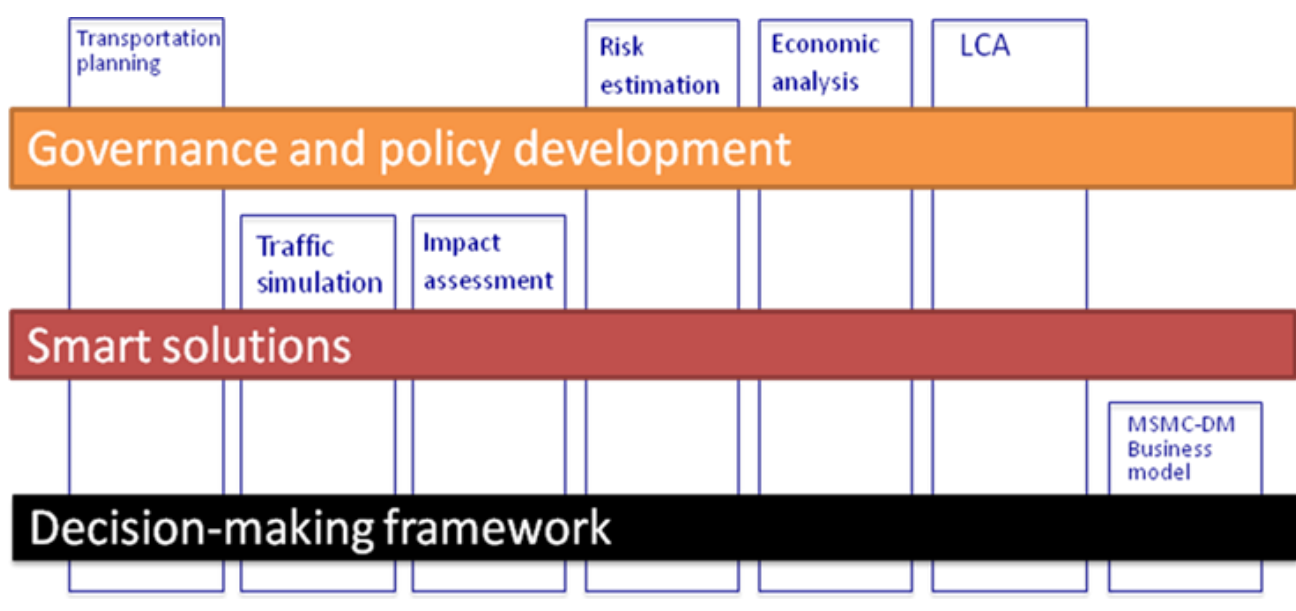

Figure 1. Main topics of the ALLIANCE project

- The $1^{\text {st }}$ topic "Governance and policy development" covers issues related to the interconnection of transportation with land use planning, legislative, institutional and organizational frameworks.

- The $2^{\text {nd }}$ topic "Smart solutions" is devoted to technological advancements and other innovative measures and tools, which enable the efficient operation of intermodal terminals and provide high quality service and environmental and energy protection and sustainability.

- The $3^{\text {rd }}$ topic "Decision making framework" is focused on tools and methods, which support decision making. In particular, covered topics here include traffic simulation and environmental impact assessment models, risk analysis tools, life-cycle analysis models and economic analysis methods. Furthermore, the area incorporates evaluation methods based on multi-stakeholder multi-criteria decision making (MSMC-DM) and sustainable business and organizational models for collaborative schemes amongst the stakeholders of the intermodal transportation chain.

The seven papers published in this Special Issue are the result of the collaboration teams' hard work and a rigorous journal's peer review process. For establishing international research teams among partners and increasing the collaborative publications in scientific journals, a special research environment has been created. In this sense, a lot of attention has been paid to knowledge sharing among partners, and facilitation of researchers to participate in International conferences and publish research articles in scientific journals.

We hope that the readers will find this Special Issue to be a useful collection of scientific papers, which provide an informative foundation to further research in this field. 
The first paper, by E. Nathanail, G. Adamos, M. Tsami, I. Yatskiv (Jackiva) (Greece, Latvia), Green Urban Interchanges: Stakeholder and User Perspectives aims at analysing the concept of "urban interchanges" as a solution towards seamless transportation and sustainable mobility and is based on an extensive review of policies, initiatives and data analysis coming from interviews and meetings with stakeholders. The comparative analysis of interchange typology performance based on the users' perception focuses on network accessibility, land uses, facilities offered for time spent at interchanges and environmentally friendly services and infrastructure. It reveals fruitful findings on proper interchange design towards sustainability and reformation of the city-hubs into true green urban interchanges.

The second paper, by M. Tsami, G. Adamos, E. Nathanail, E. Budilovich, I. Yatskiv (Jackiva), V. Magginas (Greece, Latvia), A Decision Tree Approach for Achieving High Customer Satisfaction at Urban Interchanges is the continuation of the research of authors' team in analysing the accessibility of the Riga International Coach Terminal (RICT). Authors introduced a decision tree approach, which can be used for the assessment of the design, operation and services provided at urban transport interchanges. A customer satisfaction survey was conducted about RICT users' opinion on crucial attributes and overall satisfaction. Findings revealed the most significant parameters that need to be addressed in order to increase users' satisfaction, which can gradually improve the overall attractiveness of the terminal and the efficiency of its provided services.

The third paper, by I. Kuzmina-Merlino, O. Skorobogatova, N. Schmidtke, F. Behrendt (Latvia, Germany), The Financial and Economic Aspects of Transport Infrastructure Development in Latvia is devoted to the development of transport infrastructure as a key component of the transport system of Latvia and the necessity to create an effective investment mechanism for financing the Latvian transport infrastructure as a useful instrument in making investment decisions. Based on the theory of decision making, the authors offered Investment Decision-Making Concept, which can be used when selecting investment projects in the field of transport infrastructure and their evaluation.

The fourth paper, by V. Magginas, E. Nathanail, S. Manoli, K. Malnaca (Greece, Latvia), A MultiAgent Approach towards Designing a City Port Business Model presented the design of a city port business model incorporating Public Private Partnership schemes on the basis the particular case of the port of Volos. The methodology included a multi-agent approach, using as data collection tools a passenger questionnaire survey and an interview survey targeted at port stakeholders. Authors indicated that the landlord management model would be the most effective for the particular case of the port of Volos and based on it, actions and measures improving on the port's business model were recommended.

The fifth paper, by I. Karakikes, W. Hofmann, L. Mitropoulos, M. Savrasovs (Greece, Germany, Latvia), Evaluation of Freight Measures by Integrating Simulation Tools: The Case of Volos Port, Greece presents a methodology for evaluating urban freight measures to promote sustainability in the year of 2030, using the example of the commercial port of Volos, Greece. To analyze and understand the transport network around the commercial port a traffic micro simulation software was used, while for the analysis of the intralogistics processes, a multimethod simulation software was selected. The two simulation software packages (AnyLogic and VISSIM) were integrated for evaluating a set of logistic measures in Volos Port based on environmental and transport impacts. In this case study, the results indicated that by implementing such measures, the traffic performance and the level of emissions owing to the traffic around the port in the year 2030 are significantly improved.

The sixth paper, by I. Jackson, J. Tolujevs, T. Reggelin (Latvia, Germany), The Combination of Discrete-Event Simulation and Genetic Algorithm for Solving the Stochastic Multi-Product Inventory Optimization Problem presents an eventual combination of discrete-event simulation and genetic algorithm to define the optimal inventory policy in stochastic multi-product inventory systems. The paper contains a detailed description of the optimization technique and the numerical example of six-product inventory model. The proposed approach contributes to the field of industrial engineering by providing a simple, but still efficient way to compute nearly-optimal inventory parameters with regard to risk and reliability policy. Besides, the method may be applied in automated ordering systems.

The seventh paper, by S. Trojahn (Germany), Logistics Strategies for Resource Supply Chains presents possible strategies in the field of logistics and an overview of all the important methods as well as example paths about the important dimensions that a company has to consider in terms of raw material logistics. Author shows to what extent an application of these is useful, depending on the nature of the resources, and which may not have been used in the past. 


\section{Acknowledgements}

The publishing of Special Issue of Transport and Telecommunication Journal has been supported by the ALLIANCE project (http://alliance-project.eu/) and has been funded within the European Commission's H2020 TWINNING Programme under contract number 692426. The papers express the opinions of the authors and not necessarily those of the European Commission. The European Commission is not liable for any use that may be made of the information contained in this paper. The guest editors and authors would like to thank both the project consortium and the European Commission.

We would like to thank the authors for their valuable contribution, and of course express thanks to the Transport and Telecommunication Editorial Office and the reviewers for their thoughtful suggestions and constructive criticism.

\section{References}

1. European Commission (2011) Roadmap to a Single European Transport Area - Towards a competitive and resource efficient transport system. White Paper. COM (2011) 144 final. European Commission. Brussels, Belgium.

2. Yatskiv, I., Savrasov M., Kabashkin, I., Nathanail, E., Adamos, G., Mitropoulos, L. (2017) Knowledge Sharing Strategy as a Key Element of the H2020 Programme: Enhancing Excellence and Innovation Capacity in Sustainable Transport Interchanges (Alliance) Project. Procedia Engineering. Vol. 187, pp. 458-464. doi.org/10.1016/j.proeng.2017.04.400

3. ALLIANCE Deliverable D5.5, (2016) Dissemination material 1. - www.alliance-project.eu

4. ALLIANCE Deliverable D3.1, (2016) Knowledge sharing strategy. - www.alliance-project.eu 